\title{
Associations between female lung cancer risk and sex steroid hormones: a systematic review and meta-analysis of the worldwide epidemiological evidence on endogenous and exogenous sex steroid hormones
}

Hui Zeng ${ }^{1 \dagger}$, Zhuoyu Yang ${ }^{2 \dagger}$, Jiang $\mathrm{Li}^{2}$, Yan Wen ${ }^{2}$, Zheng $\mathrm{Wu}^{2}$, Yadi Zheng ${ }^{2}$, Yiwen $\mathrm{Yu}^{2}$, Yongjie X ${ }^{2}$, Shugeng Gao ${ }^{1}$, Fengwei $\operatorname{Tan}^{1^{*}}$ (D, Ni Li ${ }^{2^{*}}$, Qi Xue ${ }^{1 *}$ and Jie He $\mathrm{H}^{1,2}$

\begin{abstract}
Background: Published findings suggest sex differences in lung cancer risk and a potential role for sex steroid hormones. Our aim was to perform a meta-analysis to investigate the effects of sex steroid hormone exposure specifically on the risk of lung cancer in women.

Methods: The PubMed, MEDLINE, Web of Science, and EMBASE databases were searched. The pooled odds ratios (ORs) and 95\% confidence intervals (95\% Cls) for female lung cancer risk associated with sex steroid hormones were calculated overall and by study design, publication year, population, and smoking status. Sensitivity analysis, publication bias, and subgroup analysis were performed.
\end{abstract}

Results: Forty-eight studies published between 1987 and 2019 were included in the study with a total of 31,592 female lung cancer cases and 1,416,320 subjects without lung cancer. Overall, higher levels of sex steroid hormones, both endogenous (OR: 0.92, 95\% Cl: 0.87-0.98) and exogenous (OR: 0.86, 95\% Cl: 0.80-0.93), significantly decreased the risk of female lung cancer by $10 \%$ (OR: 0.90, 95\% Cl: 0.86-0.95). The risk of lung cancer decreased more significantly with a higher level of sex steroid hormones in non-smoking women (OR: $0.88,95 \%$ Cl: 0.78-0.99) than in smoking women (OR: 0.98, 95\% Cl: 0.77-1.03), especially in Asia women (OR: 0.84, 95\% Cl: 0.74-0.96).

\footnotetext{
*Correspondence: tanfengwei@126.com; nli@cicams.ac.cn; xueqi@cicams.ac.cn

${ }^{+}$Hui Zeng and Zhuoyu Yang contributed equally to this work.

'Department of Thoracic Surgery, National Cancer Center/National Clinical Research Center for Cancer/Cancer Hospital, Chinese Academy of Medical Sciences and Peking Union Medical College, 17 Panjiayuan Nanli, Chaoyang District, Beijing 100021, China

${ }^{2}$ Office of Cancer Screening, National Cancer Center/National Clinical

Research Center for Cancer/Cancer Hospital, Chinese Academy of Medical Sciences and Peking Union Medical College, 17 Panjiayuan Nanli, Chaoyang

District, Beijing 100021, China
}

(c) The Author(s). 2021 Open Access This article is licensed under a Creative Commons Attribution 4.0 International License, which permits use, sharing, adaptation, distribution and reproduction in any medium or format, as long as you give appropriate credit to the original author(s) and the source, provide a link to the Creative Commons licence, and indicate if changes were made. The images or other third party material in this article are included in the article's Creative Commons licence, unless indicated otherwise in a credit line to the material. If material is not included in the article's Creative Commons licence and your intended use is not permitted by statutory regulation or exceeds the permitted use, you will need to obtain permission directly from the copyright holder. To view a copy of this licence, visit http://creativecommons.org/licenses/by/4.0/ The Creative Commons Public Domain Dedication waiver (http://creativecommons.org/publicdomain/zero/1.0/) applies to the data made available in this article, unless otherwise stated in a credit line to the data. 
Conclusions: Our meta-analysis reveals an association between higher levels of sex steroid hormone exposure and the decreased risk of female lung cancer. Surveillance of sex steroid hormones might be used for identifying populations at high risk for lung cancer, especially among non-smoking women.

Keywords: Women, Lung cancer, Sex steroid hormones, Meta-analysis

\section{Background}

Lung cancer is the leading cause of cancer-related mortality worldwide, accounting for $22 \%$ of all cancer deaths $[1,2]$. Prevention of lung cancer based on tobacco control has been widely implemented worldwide; however, approximately $25 \%$ of lung cancer cases worldwide still occur in never-smokers, especially in women [3-8]. Notably, many more lung cancer cases occur in Asian never-smokers than in Western never-smokers $[4,9]$. However, due to the uncertain causes of lung cancer besides tobacco smoking, both the primary prevention of lung cancer and lung cancer screening strategy based on the identification of high-risk populations are difficult, especially among women and never-smokers.

Knowledge about etiological and clinical lung cancer characteristics has been acquired from studies involving mainly men because of its rarity in women until the 1970s. However, the incidence of lung cancer in women has increased in recent decades [10]. Unlike lung cancer in men, in addition to less smoking, more adenocarcinoma and good prognoses have been found in lung cancer in women [11-14]. The different features existing between the genders are still unexplained, suggesting the existence of some factors associated with female lung cancer in addition to the common risk factors, such as tobacco smoking [15].

Research on the effects of sex steroid hormones on lung cancer risk might explain the sex differences of lung cancer. Biological studies have reported the expression of sex steroid hormone receptors, including estrogen, progesterone and androgen in human bronchial and alveolar epithelia and in airway smooth muscle, by which the sex steroid hormones play roles. Additionally, the presence of sex-steroid-synthesizing enzymes, as components of local metabolism in lung parenchyma, may also be involved in the development of chronic respiratory diseases, such as lung cancer [16]. These observations above have suggested that sex steroid hormones may affect the pathogenesis of lung cancer and prompt epidemiological studies to explore the associations between the levels of sex steroid hormone exposure and the risk of lung cancer in women. Additionally, increasing epidemiological evidence has shown that the levels of sex steroid hormone exposure (e.g., indicated by age at menarche, age at menopause, parity, and hormone use), might have effects on the development of lung cancer in women but with generally inconsistent findings
[6, 16-28]. Progestogens and estrogens are the main sex steroid hormone exposure in women, and according to different sources, progestogen and estrogen exposure can be roughly divided into exogenous and endogenous hormone exposure. Exogenous hormone exposure includes oral contraception (OC), use of hormone replacement therapy (HRT) and isoflavone intake from food. And endogenous hormone exposure includes younger age at menarche, older age at menopause, longer reproductive windows (only for postmenopausal women, calculated as the duration between age at menopause and age at menarche), longer menstrual cycle, pregnancy history, younger age at first pregnancy and multiple pregnancies.

The effects of sex steroid hormones on the risk of lung cancer in women are possibly influenced by study design, varied by population, and biased by tobacco smoking. To systematically analyze the associations between the levels of sex steroid hormone exposure and the risk of lung cancer in women, we conducted a meta-analysis and systematic review.

\section{Methods}

The appendix to this manuscript is publicly shared in an online repository [29]. This quantitative review is reported based on the Preferred Reporting Items for Systematic Reviews and Meta-Analysis (PRISMA) extension statement for network meta-analysis [30].

\section{Search strategy and selection criteria}

The PubMed, MEDLINE, Web of Science, and EMBASE databases were searched for articles published from January 1987 through December 2019 using the MeSH terms "menstruation," "menopause," "fertility," "hormone," "human," and "lung cancer." Potentially eligible studies were also sought regularly by computer-aided literature searches and manual searches of review articles. The detailed search strategy is shown in reference [29] (Supplementary Table S1).

In the present meta-analysis, full-text reviews were performed considering the following inclusion criteria: (1) the study reported lung cancer diagnosis along with pathological or clinical results, and (2) the study contain sex steroid hormones information in female. If data subsets were published in more than one article, only the one with the largest number of lung cancer cases was included. The exclusion criteria were as follows: (1) the 
study involved patients without primary lung cancer; (2) the study was a survival cohort study, cytotoxic molecular experiment, case report, review, or editorial; (3) the study contained data that could not be extracted or calculated from the original article; and (4) the study contain a duplicate population. All studies were stored in EndNote X9.

\section{Data extraction}

Two investigators (Hui Zeng and Zhuoyu Yang) independently extracted the data through a standardized data collection form and reached a consensus on all items. When a disagreement occurred, consensus was reached through discussion between the authors or consultation with a reviewer. Therefore, similar analytical methods could be used across all studies, and we incorporated prospective studies and case-control studies including information about lung cancer patients.

The following information was extracted from each study: the first author, calendar year of publication, study population, study design, sample sizes, whether the study had a matched design and variables used for matching, how the information on exposure was obtained (self-administered questionnaire, face-to-face interview, medical records, etc.) and the indicators of sex steroid hormones (Supplementary Table S2; Supplementary Table S3) [29]. The indicators of higher levels of endogenous sex steroid hormone exposure include younger age at menarche, older age at menopause, longer reproductive windows (only for postmenopausal women, calculated as the duration between age at menopause and age at menarche), longer menstrual cycle, pregnancy history, younger age at first pregnancy and multiple pregnancies. Meanwhile, the indicators of higher levels of exogenous sex steroid hormone exposure include use of oral contraception (OC), use of hormone replacement therapy (HRT) and isoflavone intake from food (Supplementary Table S2) [29]. Due to the inconsistency of individual study definitions of high-level hormone exposure, our classification draws on the original article classification (Supplementary Table S2) [29]. 'Ever-smokers' was defined as having smoked more than 100 cigarettes in one's lifetime. Otherwise, the cases were categorized as 'non-smokers'. If no detailed description about smoking status was available, we adopted the original definition proposed by the authors.

\section{Quality assessment}

The potential risk of bias and applicability of the included studies were assessed according to the Newcastle-Ottawa quality assessment scale. This scale comprises eight items that are classified into three domains, namely, selection, comparability and outcome. A study earning six or more stars was considered to be of high quality. The detailed process is shown in the reference [29].

\section{Statistical analysis}

A fixed-effects or random-effects model was used to pool the data based on the Mantel-Haenszel method and DerSimonian and Laird method, respectively [31, 32]. These two models provide similar results when between-studies heterogeneity is absent; otherwise, the random-effects model is more appropriate. Heterogeneity between the studies was assessed by the chi-squared $Q$ statistic (a higher number indicating more heterogeneity between studies) and $I^{2}$ value (50\% indicating heterogeneity), and $P<0.05$ was considered to indicate statistical significance. Meta-regression and subgroup analyses were performed to quantify between-study heterogeneity, which were accounted for by publication year, study population, study design, and tobacco smoking status (non- and ever-smokers). We also performed a sensitivity analysis by examining changes in the results produced by the exclusion of each study. To assess publication bias, funnel plots (the natural logarithm of the $\mathrm{OR}$ and its standard error (SE)) were constructed. The circles correspond to the log OR from individual studies, and the diagonal lines show the expected $95 \% \mathrm{CI}$ of the summary estimate. Furthermore, we performed a linear regression test of funnel plot asymmetry to evaluate more potential factors and obtained the results of Egger's test to indicate publication bias.

All statistical analyses and graphs were conducted using RevMan (Review Manager statistical software, version 5.3), R software (software, version 3.6.2, https:// www.r-project.org/) and OriginPro software (Origin Software, Inc., San Clemente, CA; version 9.6.5.169).

\section{Results}

Overall, a total of 31,592 female lung cancer cases and 1,416,320 female subjects without lung cancer were included in the meta-analysis. Anonymized information of the individual participants was obtained from 48 studies (Fig. 1) conducted in ten countries, and approximately half of them (27 of 48) were in the West. Fourteen studies were prospective studies, and the rest were case-control studies. The characteristics of the 48 studies are listed in reference [29]. In terms of quality assessment, 41 studies obtained $\geq 7$ stars, and the remaining 7 studies obtained 6 stars, indicating that the quality of the included studies was generally good (Supplementary Table S3) [29].

The present meta-analysis revealed that higher levels of sex steroid hormone exposure, both endogenous (OR: 0.92, 95\% CI: $0.87-0.98)$ and exogenous sex steroid hormones (OR: $0.86,95 \%$ CI: 0.80-0.93), significantly reduced the risk of lung cancer in women by $10 \%$ (OR: 

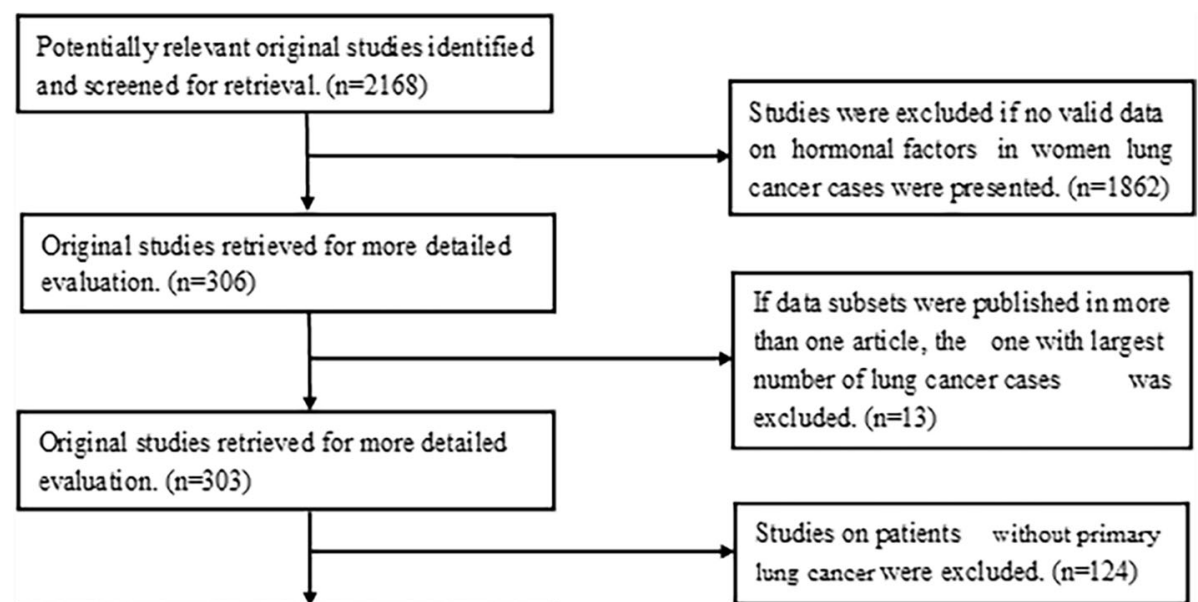

Studies on patients without primary lung cancer were excluded. ( $n=124)$

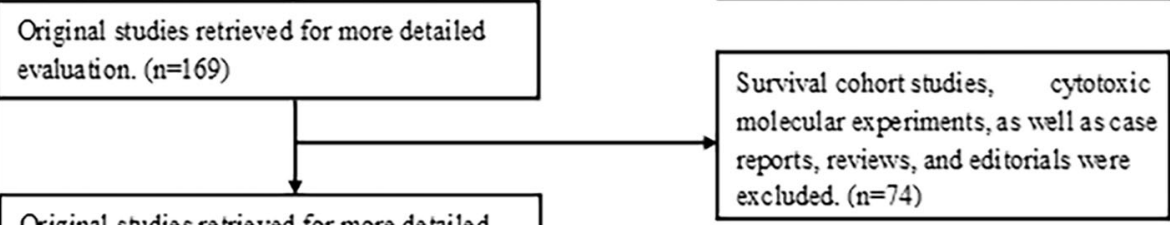

Original studies retrieved for more detailed evaluation. $(n=95)$

The study was withdrawn because detailed data could not be extracted or calculated from the original article.

Studies with useful information on both cases $(n=47)$

and controls were selected for ORs estimation of hormones on women lung cancer. $(n=48)$

Fig. 1 Flow-chart for Studies Selection

0.90, 95\% CI: 0.86-0.95). We also examined 14 studies (contained in our 48 studies) assessed both endogenous and exogenous sex steroid hormone exposure and found that higher levels of sex steroid hormone exposure reduced the risk of lung cancer in women by $11 \%$ (OR: 0.89, 95\% CI: 0.84-0.95). (Supplementary Figure S1) [29] The effects of sex steroid hormones on the risk of lung cancer did not differ significantly by publication calendar year and study design (both $P>0.05$ ) (Table 1; Supplementary Figure S2-3) [29].

Table 2 showed that, in detail, younger age at menarche (OR: 0.93, 95\% CI: 0.88-0.98), older age at menopause (OR: 0.79, 95\% CI: 0.68-0.93), longer menstrual cycle (OR: $0.75,95 \%$ CI: $0.60-0.94$ ), use of OC (OR:

Table 1 Associations between sex steroid hormones and the risk of female lung cancer

\begin{tabular}{|c|c|c|c|c|c|}
\hline Variables & No. of studies & $x^{2}$ for heterogeneity & Model selected & $\mathrm{OR}^{\mathrm{a}}\left(95 \% \mathrm{Cl}^{\mathrm{b}}\right)$ & $P$ for OR heterogeneity \\
\hline Total & 48 & 1249.27 & Random & $0.90(0.86,0.95)$ & $<.001$ \\
\hline Hormones resource & & & & & .190 \\
\hline Endogenesis & 26 & 679.81 & Random & $0.92(0.87,0.98)$ & $<.001$ \\
\hline Exogenesis & 36 & 419.73 & Random & $0.86(0.80,0.93)$ & $<.001$ \\
\hline Study design & & & & & .950 \\
\hline Retrospective & 34 & 573.55 & Random & $0.90(0.85,0.96)$ & $<.001$ \\
\hline Prospective & 14 & 667.58 & Random & $0.90(0.81,1.00)$ & $<.001$ \\
\hline Publication date & & & & & .370 \\
\hline 1987-2007 & 22 & 232.66 & Random & $0.88(0.82,0.94)$ & $<.001$ \\
\hline 2008-2019 & 26 & 1016.31 & Random & $0.92(0.86,0.99)$ & $<.001$ \\
\hline
\end{tabular}

${ }^{a}$ OR Odds ratio, ${ }^{\mathrm{b}} \mathrm{Cl}$ Confidence interval 
Table 2 Association between endogenous and exogenous sex steroid hormones and the risk of female lung cancer

\begin{tabular}{|c|c|c|c|c|c|c|}
\hline Variables & $\begin{array}{l}\text { No. of } \\
\text { studies }\end{array}$ & $\begin{array}{l}x^{2} \text { for } \\
\text { heterogeneity }\end{array}$ & $\begin{array}{l}\text { Model } \\
\text { selected }\end{array}$ & $\begin{array}{l}\mathrm{OR}^{\mathrm{a}}(95 \% \\
\left.\mathrm{Cl}^{\mathrm{b}}\right)\end{array}$ & $\begin{array}{l}P \text { for } \\
\text { heterogeneity }\end{array}$ & $\begin{array}{l}\text { Egger's test } \\
(P \text {-value })\end{array}$ \\
\hline Total & 48 & 1249.27 & Random & $\begin{array}{l}0.90(0.86, \\
0.95)\end{array}$ & $<.001$ & - \\
\hline $\begin{array}{l}\text { Indicators related to higher levels of endogenous sex } \\
\text { steroid hormone exposure }\end{array}$ & 26 & 679.81 & Random & $\begin{array}{l}0.92(0.87 \\
0.98)\end{array}$ & $<.001$ & - \\
\hline Younger age at menarche & 18 & 26.51 & Fixed & $\begin{array}{l}0.93(0.88, \\
0.98)\end{array}$ & .070 & .5729 \\
\hline Older age at menopause & 15 & 81.94 & Random & $\begin{array}{l}0.79(0.68, \\
0.93)\end{array}$ & $<.001$ & .3113 \\
\hline Longer reproductive windows & 6 & 13.34 & Random & $\begin{array}{l}0.90(0.74 \\
1.10)\end{array}$ & .020 & .0566 \\
\hline Longer menstrual cycle & 9 & 20.89 & Random & $\begin{array}{l}0.75(0.60, \\
0.94)\end{array}$ & .007 & .7938 \\
\hline History of pregnancy & 15 & 37.47 & Random & $\begin{array}{l}0.96(0.84 \\
1.10)\end{array}$ & $<.001$ & .3856 \\
\hline Younger age at first pregnancy & 15 & 69.48 & Random & $\begin{array}{l}1.21(1.05 \\
1.39)\end{array}$ & $<.001$ & .4527 \\
\hline Multiple pregnancies & 20 & 92.20 & Random & $\begin{array}{l}1.06(0.94, \\
1.19)\end{array}$ & $<.001$ & .6782 \\
\hline $\begin{array}{l}\text { Indicators related to higher levels of exogenous sex } \\
\text { steroid hormone exposure }\end{array}$ & 36 & 419.73 & Random & $\begin{array}{l}0.86(0.80 \\
0.93)\end{array}$ & $<.001$ & - \\
\hline History of use of $O C^{c}$ & 22 & 72.67 & Random & $\begin{array}{l}0.88(0.81, \\
0.96)\end{array}$ & $<.001$ & .1380 \\
\hline History of use of HRT ${ }^{d}$ & 25 & 327.30 & Random & $\begin{array}{l}0.89(0.78, \\
1.01)\end{array}$ & $<.001$ & .1725 \\
\hline Higher isoflavone intake from food & 6 & 14.37 & Random & $\begin{array}{l}0.73(0.59 \\
0.89)\end{array}$ & .010 & .9897 \\
\hline
\end{tabular}

${ }^{\mathrm{a}}$ OR Odds ratio; ${ }^{\mathrm{b}} \mathrm{Cl}$ Confidence interval, ${ }^{\mathrm{c}}$ OC Oral contraception, ${ }^{\mathrm{d}} H R T$ Hormone replacement therapy

0.88, 95\% CI: 0.81-0.96), use of HRT (OR: 0.89, 95\% CI: $0.78-1.01$ ) and higher isoflavone intake from food (OR: 0.73, 95\% CI: 0.59-0.89) significantly or borderline significantly reduced the risk of lung cancer in women. Meanwhile, younger age at first pregnancy increased the risk (OR: 1.21, 95\% CI: 1.05-1.39).

For the marked variation in characteristics of lung cancer by population, the effects of sex steroid hormones on lung cancer in women were sub-group analyzed in Asian and Western women, respectively. Overall, in both Asian (OR: 0.91, 95\% CI: 0.84-0.99) and Western (OR: 0.90, 95\% CI: 0.84-0.96) women, higher levels of sex steroid hormone exposure significantly decreased the risk of lung cancer. The sub-analysis showed that for the indicators of levels of endogenous sex steroid hormone exposure longer menstrual cycle (OR: 0.70, 95\% CI: $0.58-0.84$ ) and history of pregnancy (OR: 0.81, 95\% CI: 0.67-0.98) decreased the risk of lung cancer in Asian women, whereas older age at menopause (OR: 0.60, 95\% CI: $0.53-0.69)$ and longer reproductive windows (OR: 0.65, 95\% CI: 0.47-0.89) significantly decreased the risk of lung cancer in Western women. However, a younger age at first pregnancy increased the risk of lung cancer by $33 \%$ in the Western women (OR: 1.33 , 95\% CI: $1.18-$
1.50) (Fig. 2). For the indicators of levels of exogenous sex steroid hormone exposure, a higher isoflavone intake from food and use of OC decreased the risk of lung cancer in Asian and Western women by 30\% (OR: 0,70, 95\% CI: $0.55-0.89$ ) and $12 \%$ (OR: 0.88, 95\% CI: 0.80-0.96), respectively (Fig. 2).

Seven case-control and three prospective studies that reported the association between sex steroid hormones and female lung cancer risk by cigarettes smoking were included in the sub-group analysis for smoking [33-42]. As shown in Fig. 3, higher levels of sex steroid hormone exposure, especially the endogenous sex steroid hormones (OR: 0.86, 95\% CI: 0.75-0.98), decreased the risk of lung cancer in never-smokers more significantly (OR: 0.88, 95\% CI: 0.78-0.99). Among never-smokers, older age at menopause (OR: 1.25, 95\% CI: 1.04-1.49) and longer reproductive windows (OR: 1.22, 95\% CI: $1.01-$ 1.46) increased the risk of lung cancer. Meanwhile, a longer menstrual cycle, history of pregnancy, multiple pregnancies and higher isoflavone intake from food reduced the risk of female lung cancer by $48 \%$ (OR: 0.52 , 95\% CI: 0.37-0.74), 23\% (OR: 0.77, 95\% CI: 0.60-0.97), 27\% (OR: 0.73, 95\% CI: 0.63-0.86) and 29\% (OR: 0.71, 95\% CI: 0.58-0.87), respectively. Regarding ever- 


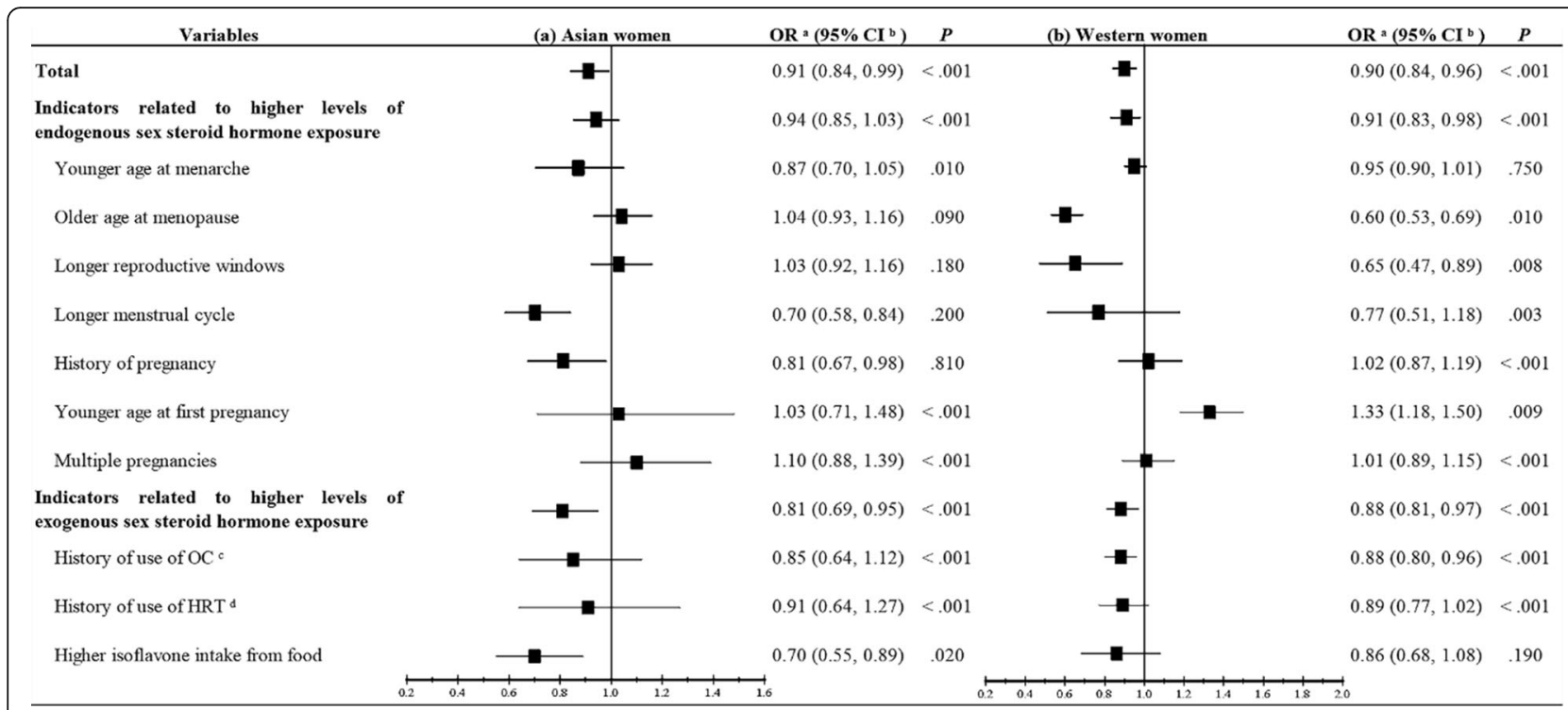

Fig. 2 Forest plots for higher levels of sex steroid hormone exposure on the risk of lung cancer with a Asian women and $\mathbf{b}$ Western women. a. OR: Odds ratio; b. Cl: Confidence interval; c. OC: Oral contraception; d. HRT: Hormone replacement therapy

smokers, significant associations were found between older age at menopause (OR: 0.76, 95\% CI: 0.60-0.96) and younger age at first pregnancy (OR: 1.39, 95\% CI: 1.05-1.85) and the risk of lung cancer (Fig. 3).

Finally, we comprehensively analyzed the risk of lung cancer in women according to both smoking status and population. Reference [29] shows that higher levels of sex steroid hormone exposure, either endogenous (OR: 0.87, 95\% CI: $0.75-1.00$ ) or exogenous (OR: 0.70, 95\% CI: $0.56-0.87)$, decreased the risk of lung cancer in non- smoking Asian women (OR: 0.84, 95\% CI: 0.74-0.96). (Supplementary Figure S4) [29].

The shape of the funnel plots (Supplementary Figure S5) [29] as well as the results of the linear regression test of funnel plot asymmetry (Supplementary Figure S6) [29] and Egger's test (Table 2) explored the absence of publication bias. The sensitivity analysis suggested that the results were robust because the pooled ORs were not obviously changed (Supplementary Figure S7) [29].

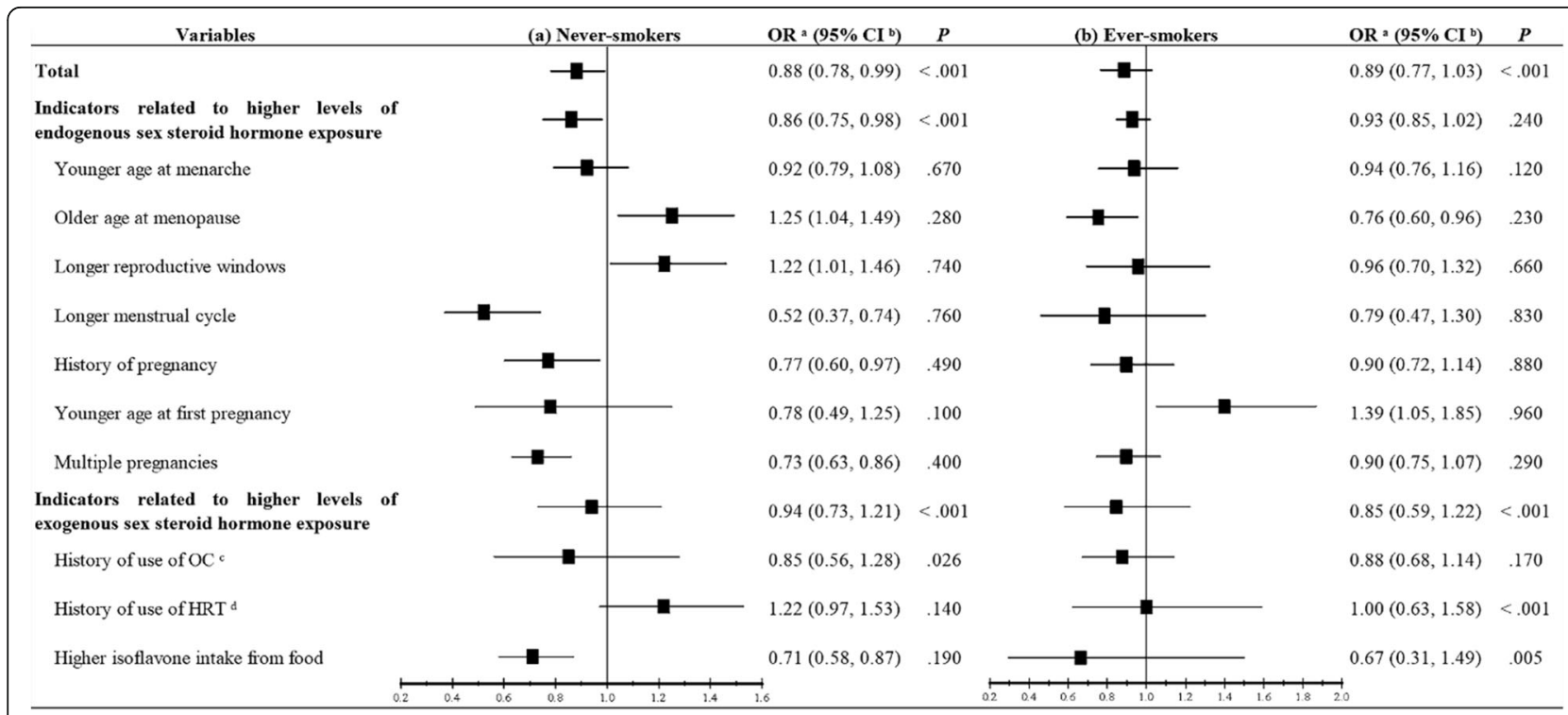

Fig. 3 Forest plots for higher levels of sex steroid hormone exposure on the risk of female lung cancer with $\mathbf{a}$ never-smokers and $\mathbf{b}$ ever-smokers. a. OR: Odds ratio; b. Cl: Confidence interval; c. OC: Oral contraception; d. HRT: Hormone replacement therapy 


\section{Discussion}

Several meta-analyses on sex steroid hormones and female lung cancer risk have been published since 2009 to 2019 , but several questions have not yet been answered [6, 16-28]. First, the previous meta-analysis only focused on the research on the exogenous sex steroid hormones (e.g., HRT use) with inconsistent conclusions. The comprehensive effect of both endogenous and exogenous sex steroid hormones on the risk of female lung cancer has not been investigated. Second, if effects of sex steroid hormones on the risk of female lung cancer exist, whether the effects are varied by race and biased by other factors such as tobacco smoking is unknown. Therefore, we conducted this study aiming to comprehensively explore the associations between the levels of sex steroid hormone exposure, both endogenous and exogenous, and the risk of lung cancer among women, including Asian and Western and ever-smokers and never-smokers. To our knowledge, this study updated previous meta-analyses by contributing a large quantity of new data and the biggest sample size on sex steroid hormone-related characteristics in female lung cancer patients published during 2006-2019, and this is the first study reporting the decreased risk of lung cancer in women related to the higher levels of sex steroid hormone exposure, both endogenous and exogenous.

The previous studies did not analyze the summary effect of both endogenous and exogenous sex steroid hormones on the risk of female lung cancer. One studies have reported their findings for menstrual factors [6, 16-28], two for reproductive histories [6, 16-28] and five for hormonal contraception use [6, 16-28]. Their results were not all the same: five studies indicated that increasing sex steroid hormone exposure was a protective factor for female lung cancer, and one studies have found that it was a risk factor; the remaining studies did not support the hypothesis that there was a clear link between sex steroid hormone exposure and lung cancer risk.

The levels of sex steroid hormone exposure vary by the stage of life in the Supplementary Figure S8 [29]. The production of endogenous female hormones begins increasingly growing at approximately the time of menarche and decreases rapidly until the time of menopause, and the intake of exogenous sex steroid hormones mainly depends on OC or HRT use and isoflavone intake. Women with a younger age at menarche as well as older age at menopause, longer reproductive window, longer length of each cycle and multiple pregnancies might have more ovulatory cycles and sex steroid secretion, resulting in higher cumulative levels of sex steroid hormone exposure. Additionally, the supplements of exogenous sex steroid hormones contribute to the cumulative exposure.
Therefore, the effect of the cumulative exposure of sex steroid hormones on the cells should be estimated overall by combining endogenous and exogenous sex steroid hormones together. Exposure to sex steroid hormones during development results in permanent organizational effects, whereas activation effects are transient and require the continued presence of the hormone [43]. Currently, the potential mechanisms underlying the association between hormone exposure and lung cancer risk are not entirely clear; in our study they mainly involve the protective roles of sex steroid hormones in lung cancer and women. Meanwhile, animal models and functional and physiological evidence provide support for a role of sex steroid hormones in lung carcinogenesis. Estrogen, progesterone and reproductive hormones are thought to be involved in the development of lung cancer due to sex differences in the protein expression of estrogen receptor (ER)- $\alpha$, ER- $\beta$, and progesterone receptor (PR) in lung cancer [16]. Localized ERs are important for alveolar formation and surfactant homeostasis in the lung, and surfactant, produced in alveolar type II cells, can clear the lungs of unwanted particles, including carcinogens [44]. A decreased risk of lung cancer was reported in ER-positive women on HRT. The use of HRT was proven to be associated with the increased levels of estrogen binding to ER- $\beta$ in the lung, reducing transcription and thus reducing cell growth [45]. Some studies showed that use of HRT and a higher level of ER expression could enhance the ability of the immune system to reject malignant lung tissues early in the cancer process [46-49]. Meanwhile, the endogenous hormones, indicated by menstrual factors, might influence the role of estrogens in epithelial cell regeneration and maintenance [44]. The biology of sex steroid hormones in women is undoubtedly complex and includes enzymes involved in metabolism, receptors, regulation and crosstalk with other signaling pathways. In addition, the potential differences in the mechanisms between endogenous and exogenous hormones deserve further study.

The effects of sex steroid hormones on the risk of female lung cancer did not differ by calendar year of publication and the study design, suggesting robust associations between the decreased risk of lung cancer in women and higher levels of sex steroid hormone exposure. However, the effects vary by population and race. Older age at menopause and longer reproductive windows significantly decreased the risk of lung cancer in Western women but not in Asian women. The differences in the use of HRT between Asian and Western women might explain this finding partly. The use of HRT is more common in Western women 
than in Asian women, which is consistent with our findings that HRT use is a protective factor [50]. Additionally, ethnic genetic backgrounds and lifestyle differences should be also considered.

Tobacco smoking, the most established risk factor for lung cancer, confounds the effects of sex steroid hormones on the risk of female lung cancer. Peng J et al. reported enhanced estrogenic synthesis in lung cancer tissues, and their hormonal environment can synergize with the mutagenicity of tobacco smoke components [51]. Although the higher levels of sex steroid hormone exposure reduced the risk of female lung cancer in both never-smokers and ever-smokers, the association appears more pronounced for never-smokers, especially in Asians. Interestingly, older age at menopause, an indicator of lower risk of lung cancer in female ever-smokers, is an indicator for higher risk in never-smokers. This finding might be attributed to the higher proportion of never-smokers in Asian females and the less use of exogenous sex steroid hormones [6-8, 50, 52].

This study explored the correlation between sex steroid hormone exposure and the risk of lung cancer risk in women, especially in never-smoking and Asian women. We would also suggest expanding on the challenges for recruiting female non-smokers into the screening under the current screening strategy. Currently, the LDCT scan is the only official method of lung cancer screening. However, to reduce the harms of screening such as false positives, overdiagnosis and treatment, economic burden and radiation exposure, a risk assessment customized to the target population is essential. Identifying never-smokers with a cancer risk as high as those within ever-smokers who may similarly benefit from LDCT screening is an urgent matter to accommodate "equal management of people at equal risk". This study provides evidence for exploring new risk factors of lung cancer and developing risk-assessment-based lung cancer screening strategies. This study had some limitations. First, more precise evaluation of the association, including the dose-response and a time-response relationship, could not be evaluated, due to the lack of fine data acquisition from the individual original studies, such as histologic types and hormone receptor status of lung cancer cases. Second, although the meta-analysis includes more than 30,000 female lung cancer cases and $1,400,000$ subjects without lung cancer, the multiple sub-analyses are relatively less robust because of the limited ample size. Third, cut-off value for young age among the included studies was variable and not standardized. The most used cut-off value was the original definition proposed by the authors, but they varied among the included studies. Fourth, studies without original data have been excluded, which may lead to heterogeneity and possible selection bias. However, the conclusions and limitations of this study may provide some directions for the design of new trials.

\section{Conclusions}

In summary, this meta-analysis revealed an association between higher levels of sex steroid hormone exposure and a decreased risk of female lung cancer, but the molecular biological mechanisms deserve further study. Surveillance of sex steroid hormones might be used for identifying populations at high risk of lung cancer, especially among non-smoking women. Future biological studies on the mechanism and epidemiological studies with improved design and fewer confounding factors are needed to understand the relationship between sex steroid hormones and lung cancer.

\section{Abbreviations}

95 \% Cl: 95 \% confidence interval; OR: Odds ratio; OC: Oral contraceptive; HRT: Hormone replacement therapy

\section{Supplementary Information}

The online version contains supplementary material available at https://doi. org/10.1186/s12885-021-08437-9.

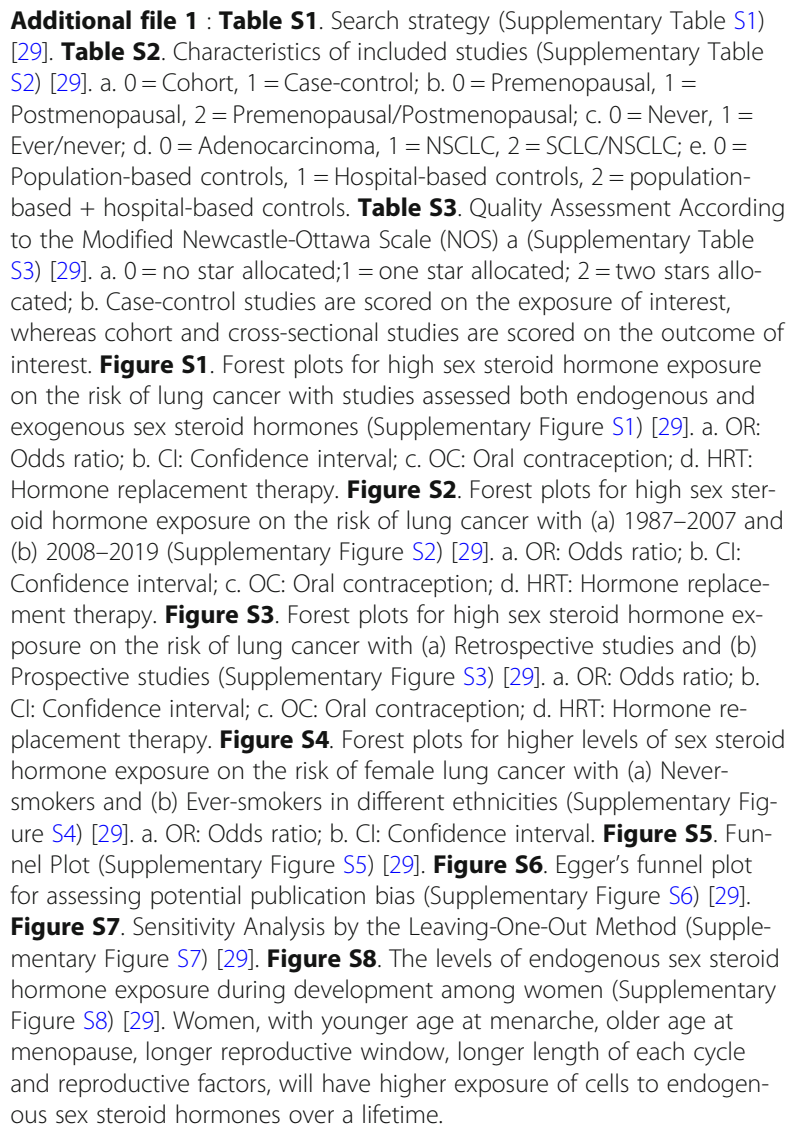

\section{Acknowledgements}

We are grateful to Zhangyan Lyu and Xiaoshuang Feng for advices relating to the citation searches of the electronic databases and the analysis. 


\section{Authors' contributions}

FT, NL, QX and JH conceived and designed the study; YY, YX, SG and WZ provided study materials and tools; $H Z, Z Y, J L, Y W$ and $Y Z$ responsible for the collection and assembly of data, data analysis, and interpretation; $\mathrm{HZ}$ and $\mathrm{ZY}$ were involved in writing the manuscript; $\mathrm{FT}, \mathrm{NL}, \mathrm{QX}$ and JH revised the manuscript. All the work was performed under FT, NL and QX's instruction. All authors read and approved the final manuscript.

\section{Funding}

This work was supported by the National Key R\&D Program of China (2018YFC1315000/01/03, 2017YFC0907900/01 and 2016YFC1302500/05); the National Natural Science Foundation of China (81871885); the Non-profit Central Research Institute Fund of Chinese Academy of Medical Sciences (2019PT320027, 2019PT320023, 3332019005, 2018RC330002 and 2018RC320010); the CAMS Innovation Fund for Medical Sciences (No. 2019I2M-2-002); the Training Program Foundation for the Talents in Beijing City (2017000021223TD05); the PUMC Youth Fund (2017320013); the Special Foundation for Central Committee Health Care (W2017BJ39); the Beijing Science and Technology Project (Z181100001718212); the Scientific Research of Cancer Hospital (Institute) on Chinese Academy of Medical Sciences (LC2017A01). The study funders had no role in the design, data acquisition, analyses, or data interpretation of this project.

\section{Availability of data and materials}

The dataset supporting the conclusions of this article is available in the references and the supplementary information, unique persistent identifier and hyperlink to dataset(s) in https://doi.org/10.6084/m9.figshare.12991559. v2.

\section{Declarations}

\section{Ethics approval and consent to participate} Not applicable.

\section{Consent for publication}

Not applicable.

\section{Competing interests}

The authors declare no conflict of interest.

Received: 2 March 2021 Accepted: 3 June 2021

Published online: 10 June 2021

\section{References}

1. Torre LA, Bray F, Siegel RL, Ferlay J, Lortet-Tieulent J, Jemal A. Global cancer statistics, 2012. CA Cancer J Clin. 2015;65(2):87-108. https://doi.org/10.3322/ caac. 21262

2. Siegel RL, Miller KD, Jemal A. Cancer statistics, 2020. CA Cancer J Clin. 2020; 70(1):7-30. https://doi.org/10.3322/caac.21590

3. Chien LH, Chen $\mathrm{CH}$, Chen TY, Chang GC, Tsai YH, Hsiao CF, et al. Predicting Lung Cancer Occurrence in Never-Smoking Females in Asia: TNSF-SQ, a Prediction Model. Cancer Epidemiol Biomarkers Prevention. 2020;29(2):452-9.

4. Sun S, Schiller JH, Gazdar AF. Lung cancer in never smokers - a different disease. Nat Rev Cancer. 2007:7(10):778-90. https://doi.org/10.1038/nrc2190.

5. Ferlay J, Shin HR, Bray F, Forman D, Mathers C, Parkin DM. Estimates of worldwide burden of cancer in 2008: GLOBOCAN 2008. Int J Cancer. 2010; 127(12):2893-917. https://doi.org/10.1002/ijc.25516.

6. Bae JM. Modifiable risk factors of lung cancer in "never-smoker" women. Epidemiol Health. 2015;37:e2015047. https://doi.org/10.4178/epih/e2015047.

7. Bravo-Iniquez CE, Fox SW, De Leon LE, Tarascio JN, Jaklitsch MT, Jacobson FL. Cumulative nonsmoking risk factors increase the probability of developing lung cancer. J Thorac Cardiovasc Surg. 2019;158(4):1248-1254. e1.

8. Wakelee HA, Chang ET, Gomez SL, Keegan TH, Feskanich D, Clarke CA, et al. Lung cancer incidence in never smokers. J Clin Oncol. 2007;25(5):472-8. https://doi.org/10.1200/JCO.2006.07.2983.

9. Yano T, Miura N, Takenaka T, Haro A, Okazaki H, Ohba T, et al. Neversmoking nonsmall cell lung cancer as a separate entity: clinicopathologic features and survival. Cancer. 2008:113(5):1012-8. https://doi.org/10.1002/ cncr.23679.
10. Bade BC, Dela Cruz CS. Lung cancer 2020: epidemiology, etiology, and prevention. Clin Chest Med. 2020;41(1):1-24. https://doi.org/10.1016/j.ccm.2 019.10.001.

11. Siddiqui F, Bae K, Langer CJ, Coyne JC, Gamerman V, Komaki R, et al. The influence of gender, race, and marital status on survival in lung cancer patients: analysis of radiation therapy oncology group trials. J Thorac Oncol. 2010;5(5):631-9. https://doi.org/10.1097/JTO.0b013e3181d5e46a.

12. Ou SH, Zell JA, Ziogas A, Anton-Culver H. Prognostic factors for survival of stage I nonsmall cell lung cancer patients : a population-based analysis of 19,702 stage I patients in the California Cancer registry from 1989 to 2003 Cancer. 2007;110(7):1532-41. https://doi.org/10.1002/cncr.22938.

13. Kawaguchi T, Takada M, Kubo A, Matsumura A, Fukai S, Tamura A, et al. Performance status and smoking status are independent favorable prognostic factors for survival in non-small cell lung cancer: a comprehensive analysis of 26,957 patients with NSCLC. J Thorac Oncol. 2010;5(5):620-30. https://doi.org/10.1097/JTO.0b013e3181d2dcd9.

14. Henschke Cl, Yip R, Miettinen OS. Women's susceptibility to tobacco carcinogens and survival after diagnosis of lung cancer. Jama. 2006;296(2): 180-4. https://doi.org/10.1001/jama.296.2.180.

15. Corrales L, Rosell R, Cardona AF, Martin C, Zatarain-Barron ZL, Arrieta O. Lung cancer in never smokers: the role of different risk factors other than tobacco smoking. Crit Rev Oncol Hematol. 2020;148:102895. https://doi. org/10.1016/j.critrevonc.2020.102895.

16. Cheng TD, Darke AK, Redman MW, Zirpoli GR, Davis W, Payne Ondracek R, et al. Smoking, sex, and non-small cell lung cancer: steroid hormone receptors in tumor tissue (S0424). J Natl Cancer Inst. 2018;110(7):734-42. https://doi.org/10.1093/jnci/djx260.

17. Gao YT, Blot WJ, Zheng W, Ershow AG, Hsu CW, Levin LI, et al. Lung cancer among Chinese women. Int J Cancer. 1987;40(5):604-9. https://doi.org/10.1 002/ijc.2910400505.

18. Jin C, Lang B. Hormone replacement therapy and lung cancer risk in women: a meta-analysis of cohort studies: hormone replacement therapy and lung cancer risk. Medicine. 2019;98(51):e17532. https://doi.org/10.1097/ MD.0000000000017532.

19. Min L, Wang F, Liang S, Yang J, Xu X. Menopausal status and the risk of lung cancer in women: a PRISMA-compliant meta-analysis. Medicine. 2017; 96(26):e7065. https://doi.org/10.1097/MD.0000000000007065.

20. Weiss JM, Lacey JV Jr, Shu XO, Ji BT, Hou L, Yang G, et al. Menstrual and reproductive factors in association with lung cancer in female lifetime nonsmokers. Am J Epidemiol. 2008;168(11):1319-25. https://doi.org/10.1 093/aje/kwn257.

21. Oh SW, Myung SK, Park JY, Lym YL, Ju W. Hormone therapy and risk of lung cancer: a meta-analysis. J Women's Health (2002). 2010;19(2):279-88.

22. Zhang $Y$, Yin Z, Shen $L$, Wan $Y$, Zhou B. Menstrual factors, reproductive factors and lung cancer risk: a meta-analysis. Zhongguo Fei Ai Za Zhi. 2012; 15(12):701-19. https://doi.org/10.3779/j.issn.1009-3419.2012.12.04.

23. Honma N, Hosoi T, Arai T, Takubo K. Estrogen and cancers of the colorectum, breast, and lung in postmenopausal women. Pathol Int. 2015 65(9):451-9. https://doi.org/10.1111/pin.12326

24. Bae JM, Kim EH. Hormonal replacement therapy and the risk of lung cancer in women: an adaptive meta-analysis of cohort studies. J Prev Med Public Health. 2015;48(6):280-6.

25. Pesatori AC, Carugno M, Consonni D, Hung RJ, Papadoupolos A, Landi MT, et al. Hormone use and risk for lung cancer: a pooled analysis from the international lung cancer consortium (ILCCO). Br J Cancer. 2013;109(7):195464. https://doi.org/10.1038/bjc.2013.506.

26. Yao Y, Gu X, Zhu J, Yuan D, Song Y. Hormone replacement therapy in females can decrease the risk of lung cancer: a meta-analysis. PLoS One. 2013;8(8):e71236. https://doi.org/10.1371/journal.pone.0071236.

27. Dahabreh IJ, Trikalinos TA, Paulus JK. Parity and risk of lung cancer in women: systematic review and meta-analysis of epidemiological studies. Lung Cancer (Amsterdam, Netherlands). 2012;76(2):150-8.

28. Wu W, Yin ZH, Guan P, Ren YW, Zhou BS. Association of oral contraceptives use and lung cancer risk among women: an updated meta-analysis based on cohort and case-control studies. Asian Pac J Cancer Prev. 2014;15(3): 1205-10. https://doi.org/10.7314/APJCP.2014.15.3.1205.

29. Zeng H. Supplementary_Material.pdf. figshare. Dataset; 2020. https://doi. org/10.6084/m9.figshare.12991559.v2.

30. Hutton B, Salanti G, Caldwell DM, Chaimani A, Schmid CH, Cameron C, et al. The PRISMA extension statement for reporting of systematic reviews incorporating network meta-analyses of health care interventions: checklist 
and explanations. Ann Intern Med. 2015;162(11):777-84. https://doi.org/10. 7326/M14-2385.

31. Mantel $\mathrm{N}$, Haenszel W. Statistical aspects of the analysis of data from retrospective studies of disease. J Natl Cancer Inst. 1959;22(4):719-48.

32. DerSimonian R, Kacker R. Random-effects model for meta-analysis of clinical trials: an update. Contemp Clin Trials. 2007;28(2):105-14. https://doi.org/10.1 016/j.cct.2006.04.004.

33. Jin $\mathrm{K}$, Wu M, Zhou JY, Yang J, Han RQ, Jin ZY, et al. Tobacco smoking modifies the association between hormonal factors and lung cancer occurrence among post-menopausal Chinese women. Transl Oncol. 2019; 12(6):819-27. https://doi.org/10.1016/j.tranon.2019.03.001.

34. Lim WY, Chen Y, Chuah KL, Eng P, Leong SS, Lim E, et al. Female reproductive factors, gene polymorphisms in the estrogen metabolism pathway, and risk of lung cancer in Chinese women. Am J Epidemiol. 2012; 175(6):492-503. https://doi.org/10.1093/aje/kwr332.

35. Meinhold CL, Berrington de Gonzalez A, Bowman ED, Brenner AV, Jones RT, Lacey JV Jr, et al. Reproductive and hormonal factors and the risk of nonsmall cell lung cancer. Int J Cancer. 2011;128(6):1404-13. https://doi. org/10.1002/ijc.25434.

36. Seow A, Poh WT, Teh M, Eng P, Wang YT, Tan WC, et al. Diet, reproductive factors and lung cancer risk among Chinese women in Singapore: evidence for a protective effect of soy in nonsmokers. Int J Cancer. 2002;97(3):365-71. https://doi.org/10.1002/ijc.1615.

37. Brinton LA, Gierach GL, Andaya A, Park Y, Schatzkin A, Hollenbeck AR, et al. Reproductive and hormonal factors and lung cancer risk in the NIH-AARP diet and health study cohort. Cancer Epidemiol Biomarkers Prev. 2011;20(5): 900-11. https://doi.org/10.1158/1055-9965.EPI-10-1325.

38. Paulus JK, Asomaning K, Kraft P, Johnson BE, Lin X, Christiani DC. Parity and risk of lung cancer in women. Am J Epidemiol. 2010;171(5):557-63. https:// doi.org/10.1093/aje/kwp441.

39. Rodriguez C, Spencer Feigelson H, Deka A, Patel AV, Jacobs EJ, Thun MJ, et al. Postmenopausal hormone therapy and lung cancer risk in the cancer prevention study II nutrition cohort. Cancer Epidemiol Biomarkers Prev. 2008;17(3):655-60. https://doi.org/10.1158/1055-9965.EPI-07-2683.

40. Schabath MB, Wu X, Vassilopoulou-Sellin R, Vaporciyan AA, Spitz MR. Hormone replacement therapy and lung cancer risk: a case-control analysis. Clin Cancer Res. 2004;10(1 Pt 1):113-23. https://doi.org/10.1158/1078-0432. CCR-0911-3.

41. Schabath MB, Hernandez LM, Wu X, Pillow PC, Spitz MR. Dietary phytoestrogens and lung cancer risk. Jama. 2005;294(12):1493-504. https:// doi.org/10.1001/jama.294.12.1493.

42. Shimazu T, Inoue M, Sasazuki S, Iwasaki M, Sawada N, Yamaji T, et al. Isoflavone intake and risk of lung cancer: a prospective cohort study in Japan. Am J Clin Nutr. 2010;91(3):722-8. https://doi.org/10.3945/ajcn.2009.2 8161.

43. Arroyo P, Ho BS, Sau L, Kelley ST, Thackray VG. Letrozole treatment of pubertal female mice results in activational effects on reproduction, metabolism and the gut microbiome. PLoS One. 2019;14(9):e0223274. https://doi.org/10.1371/journal.pone.0223274.

44. Patrone C, Cassel TN, Pettersson K, Piao YS, Cheng G, Ciana P, et al. Regulation of postnatal lung development and homeostasis by estrogen receptor beta. Mol Cell Biol. 2003;23(23):8542-52. https://doi.org/10.1128/ MCB.23.23.8542-8552.2003.

45. Murugappan G, Li S, Lathi RB, Baker VL, Eisenberg ML. Risk of cancer in infertile women: analysis of US claims data. Hum Reprod (Oxford, England). 2019;34(5):894-902.

46. Siegfried JM, Stabile LP. Estrongenic steroid hormones in lung cancer. Semin Oncol. 2014;41(1):5-16. https://doi.org/10.1053/j.seminoncol.2013.12. 009.

47. Slowikowski BK, Lianeri M, Jagodzinski PP. Exploring estrogenic activity in lung cancer. Mol Biol Rep. 2017;44(1):35-50. https://doi.org/10.1007/s11033016-4086-8.

48. Kadota K, Eguchi T, Villena-Vargas J, Woo KM, Sima CS, Jones DR, et al. Nuclear estrogen receptor-alpha expression is an independent predictor of recurrence in male patients with pT1aNO lung adenocarcinomas, and correlates with regulatory T-cell infiltration. Oncotarget. 2015;6(29):27505-18. https://doi.org/10.18632/oncotarget.4752.

49. Grivennikov SI, Greten FR, Karin M. Immunity, inflammation, and cancer. Cell. 2010;140(6):883-99. https://doi.org/10.1016/j.cell.2010.01.025.

50. Chu K, Song Y, Chatooah ND, Weng Q, Ying Q, Ma L, et al. The use and discontinuation of hormone replacement therapy in women in South
China. Climacteric. 2018;21(1):47-52. https://doi.org/10.1080/13697137.201 7.1397622.

51. Peng J, Xu X, Mace BE, Vanderveer LA, Workman LR, Slifker MJ, et al. Estrogen metabolism within the lung and its modulation by tobacco smoke. Carcinogenesis. 2013;34(4):909-15. https://doi.org/10.1093/carcin/ bgs402.

52. Liu S, Zhang M, Yang L, Li Y, Wang L, Huang Z, et al. Prevalence and patterns of tobacco smoking among Chinese adult men and women: findings of the 2010 national smoking survey. J Epidemiol Community Health. 2017;71(2):154-61. https://doi.org/10.1136/jech-2016-207805.

\section{Publisher's Note}

Springer Nature remains neutral with regard to jurisdictional claims in published maps and institutional affiliations.
Ready to submit your research? Choose BMC and benefit from:

- fast, convenient online submission

- thorough peer review by experienced researchers in your field

- rapid publication on acceptance

- support for research data, including large and complex data types

- gold Open Access which fosters wider collaboration and increased citations

- maximum visibility for your research: over $100 \mathrm{M}$ website views per year

At $\mathrm{BMC}$, research is always in progress.

Learn more biomedcentral.com/submissions 